\title{
NUTRITIONAL ASSESSMENT OF CHILDREN LESS THAN TWO YEARS OF AGE IN A RURAL AREA IN KERALA
}

\author{
Shamim S1, Sheela T. $A^{2}$
}

1Specialist Paediatrician, Department of Paediatrics, Al Samaa Group of Hospitals, Al, Khuwair, Muscat, Oman.

${ }^{2}$ Associate Professor, Department of Paediatrics, Government Medical College, Thrissur, Kerala, India.

ABSTRACT
BACKGROUND
Adequate nutrition is critical to child development especially from birth to two years of age. In India, about 65 percent of under five
children suffer from varying degrees of malnutrition. The health indicators of Kerala are higher compared to other states in India,
there are certain backward pockets mostly in slums, coastal and tribal settlements. The objective is to study the nutritional profile
of children less than 2 years from a rural area in Kerala.

\section{MATERIALS AND METHODS}

Children of 1 to 24 months of age were included from Talikulam Panchayath, a rural area in the district of Thrissur, Kerala. Weight, height and mid arm circumference were analysed by using WHO Z scores \& IAP classification. The degree of stunting and wasting were categorized as per Waterlow's classification. Relation of low birth weight and exclusive breast feeding with malnutrition were also studied.

\section{RESULTS}

Out of 376 children $19.9 \%$ came under mild PEM, 6.1\% moderate and $1.3 \%$ with severe malnutrition and $72.7 \%$ had no malnutrition according to IAP classification. 33.5\% had first degree stunting, and 3.2\% had second degree stunting and no stunting in $62.5 \% .20 .5$ $\%$ had grade 1 wasting. Measurement of Mid Arm Circumference showed 37.6\% moderate PEM and $7 \%$ severe PEM. 88.5\% had birth weight $\geq 2.5 \mathrm{~kg}$ and $11.5 \%$ had low birth weight. In the normal birth weight category, $74.8 \%$ had normal weight for age, while within low birth weight, only 53.5\% were normal. Only 40.8\% were exclusively breastfed for 6 months and received appropriate complementary feeding. In $<6$ months age group, the prevalence of PEM was higher using WHO standards than using IAP.

\section{CONCLUSION}

The prevalence of under nutrition in 1-24 months of age is $27.7 \%$ as per IAP standards and $22.4 \%$ by WHO- Z score. More stunting in females. Low birth weight has statistically significant association with PEM. Only $41 \%$ of children are exclusively breast fed for six months. $37.5 \%$ of children are stunted indicating greater degree of chronic malnutrition.

\section{KEY WORDS}

Protein Energy Malnutrition, Stunting, Wasting, Mid Arm Circumference.

HOW TO CITE THIS ARTICLE: Shamim S, Sheela TA. Nutritional assessment of children less than two years of age in a rural area in Kerala. J. Evolution Med. Dent. Sci. 2018;7(52):5549-5554, DOI: 10.14260/jemds/2018/1228

\section{BACKGROUND}

Under nutrition continues to be a widespread problem in India, despite significant improvement in food production and advancement in science. ${ }^{1} 112.8$ million under-five children in the country are moderately or severely stunted, accounting for $38 \%$ of the global burden. We have failed to achieve any remarkable progress in infant feeding practices, with only a small increment being recorded in the exclusive breastfeeding rates amongst infants 0-6 months of age from $41.2 \%$ in 199899 to $46.3 \% \%$ in $2005-2006$ (NFHS- 2, 3). ${ }^{2}$ Early initiation of breastfeeding stands low at $24.5 \%$ and the median duration of EBF among last-born children is as brief as two months.

'Financial or Other Competing Interest': None.

Submission 16-07-2018, Peer Review 06-12-2018,

Acceptance 12-12-2018, Published 24-12-2018.

Corresponding Author:

Dr. Sheela T. A,

$S A D^{\prime} R .55 / 1188$

Aliya Gardens,

Panjikal Ayyanthole,

Thrissur, Kerala, India.

E-mail: sheelathepararambil@gmail.com

DOI: $10.14260 /$ jemds/2018/1228

\section{(c) (1) () $\Theta$}

It has been shown that only $53 \%$ infants had received complementary feeding between 6-8 months, about $44 \%$ of breastfed children being fed at least the minimum number of times recommended, ${ }^{2}$ only $21 \%$ children are fed in accordance with the infant and young child feeding (IYCF) recommendations. Under nutrition is an outcome of household level food security, access to health and sanitation services, and child rearing practices. ${ }^{3}$ Low dietary intake, infectious diseases, lack of appropriate care, and inequitable distribution of food within the household are other contributing factors.

Nutritional deficiencies in India are evident right from the time of birth. Stunting and underweight manifests are early along with lack of cognitive and social stimulation. ${ }^{4}$ Adequate nutrition is critical to from birth to two years of age during which the rapid brain growth and myelination occurs. ${ }^{5}$ About 65 percent of under five children suffer from varying degrees of protein energy malnutrition in the country which has lifelong negative impact on educational performance and psycho-social functioning.6,7 Many poor nutritional outcomes begin in utero and are manifest as Low birth weight (LBW). Prematurity and intrauterine growth retardation (IUGR) are the two main causes of LBW. ${ }^{8}$

In rural areas, half of young children are stunted, almost half are underweight, and one out of every five is wasted. Birth 
weight is an important indicator of a child's risk of childhood illnesses. Almost half of children with a low birth weight are currently stunted or underweight, compared with about onethird of children with a birth weight of $2.5 \mathrm{~kg}$ or more.

Though the Health indicators of Kerala are higher, compared to other states in India, there are certain backward pockets mostly in slums, coastal and tribal settlements. Recent incidences of Protein Energy Malnutrition in certain tribal population in Kerala should be an eye opener. PEM is more prevalent in the weaning and post weaning phase, and children in the age group ( 1 month to 24 months) was selected for the study.

\section{Aims and Objectives}

1. To study the nutritional profile (Degree of Protein Energy Malnutrition of children less than 2 years of age in a rural area in Kerala.

2. To compare the factors like birth weight and duration of exclusive breastfeeding that affects the nutritional status of children.

\section{MATERIALS \& METHODS}

\section{Study Design}

Cross sectional descriptive study.

\section{Study Setting}

Talikulam Panchayat, a rural area situated in the coastal belt of Thrissur district, Kerala.

\section{Duration of the Study}

November 2012 to April 2013(6 months)

\section{Study Subjects}

Randomly selected children less than two years.

\section{Inclusion Criteria}

Children between 1 month \& 24 months of age

\section{Exclusion Criteria}

1. Children with chronic systemic illness.

2. Those who did not give consent for the study.

\section{Justification for Sample Size}

Sample size taken for convenience and the sampling was also done for convenient.

\section{Method of Sample Collection}

Based on the maternal and child health register of the $\mathrm{PHC}$ a sampling frame of all the children less than 2 years was prepared. The participants were selected by simple random sampling using random number. The selected children were contacted, and their mothers were interviewed. 376 children were included in the study out of 383 children enrolled, 7 children having systemic illness were excluded and 3 for not giving consent.

The anthropometric measurements viz. weight, height and mid arm circumference were taken for assessing the growth were analysed by computing the weight for age, height for age and weight for height and classified according to WHO Z score \& IAP classification. The degree of stunting and wasting were categorized as per Waterlow's classification. Relation of low birth weight and malnutrition and exclusive breast feeding, and malnutrition were studied.

Mid Arm Circumference measured using non-stretchable tape. This measurement was taken only for the 13-24-month age group. Relation of low birth weight and malnutrition was studied. For this low birth weight was defined as $\leq 2.5 \mathrm{~kg}$, birth weight $>2.5 \mathrm{~kg}$ was taken as normal.

To study the relation between duration of exclusive breastfeeding and malnutrition, only the children in the 7-24month age group were taken into account. Exclusive breast feeding for six months followed by introduction of semisolids is considered as the optimal period of exclusive breast feeding.

\section{Statistical Analysis}

Analysis was done using the software SPSS 10. Data was analysed using percentage and frequency by chi sequence test. The significance level kept at 5\%.

\section{RESULTS}

Of the total 376 children, $49.5 \%$ were in the 13 -24-month age group, $34.5 \%$ in $7-12$-month age group and $16 \%$ in 1-6-month age group. Males constituted 49\% (183) and females 51\% (193). $72.3 \%$ (272) had no undernutrition; $19.9 \%$ came under mild protein energy malnutrition; $6.1 \%$ with moderate malnutrition and $1.3 \%$ with severe malnutrition according to IAP classification.

Total no of children with different grades of PEM- (WHO classification. $(n=376)$

\begin{tabular}{|c|c|c|}
\hline Grading/Z Score & Frequency & Percent \\
\hline -2 to+2 Z Score (Normal) & 292 & 77.7 \\
\hline -2 to -3 Z Score (Moderate PEM) & 69 & 18.4 \\
\hline <- 3 Z Score (Severe PEM) & 15 & 4.0 \\
\hline Total & $\mathbf{3 7 6}$ & $\mathbf{1 0 0 . 0}$ \\
\hline
\end{tabular}

*Total no of children with different grades of PEM- (WHO classification. ( $\mathrm{n}=376)+77.7 \%$ of total children were normal; $18.4 \%$ had moderate PEM and $4 \%$ had severe malnutrition

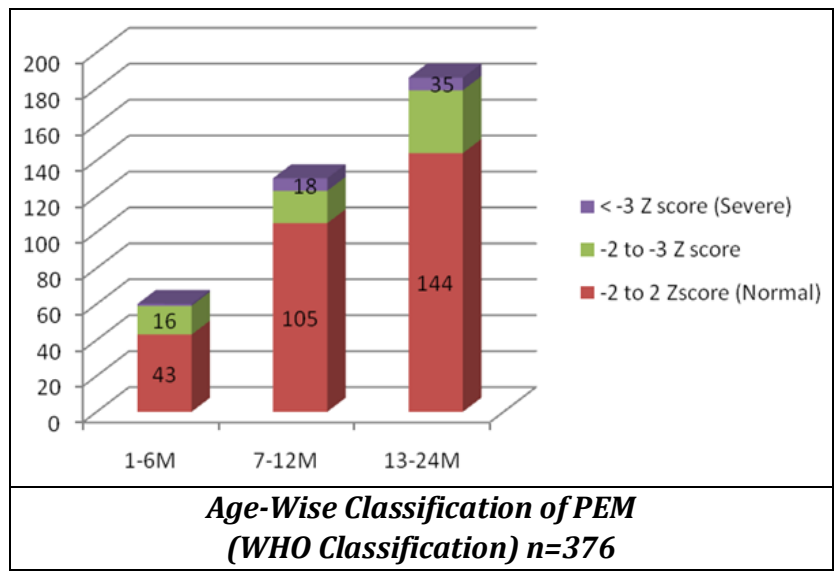

*Age-wise classification of PEM (WHO classification) $\mathrm{n}=376-\dagger 1-6 \mathrm{M}$ age group -43 (71.6\%) normal, 16 (26.6\%) moderate PEM \&1(1.6 \%) severe PEM. $\neq 7-12 \mathrm{M}$ age group 105 (81\%) had no malnutrition \& 18(14\%) moderate malnutrition. $\S 13-24 \mathrm{M}$ age group-144 (77.4\%) were normal $35(19 \%)$ with moderate malnutrition.

According to sex wise classification as per IAP out of 183 male children, $148(80.8 \%)$ had no undernutrition. 26 males (14\%) had grade 1 PEM and 8 male children (4\%) had grade 2 PEM. Among 193 female children, 124 (64\%) were normal, 
$49(25 \%)$ with grade 1 PEM and $15(7 \%)$ with grade 2 PEM. Of the 183 males, 149 (81.4\%) were normal and 29 (15.8\%) had moderate malnutrition. Among 193 females, 143 (74\%) had no malnutrition and $40(20.7 \%)$ had moderate PEM according to WHO classification.

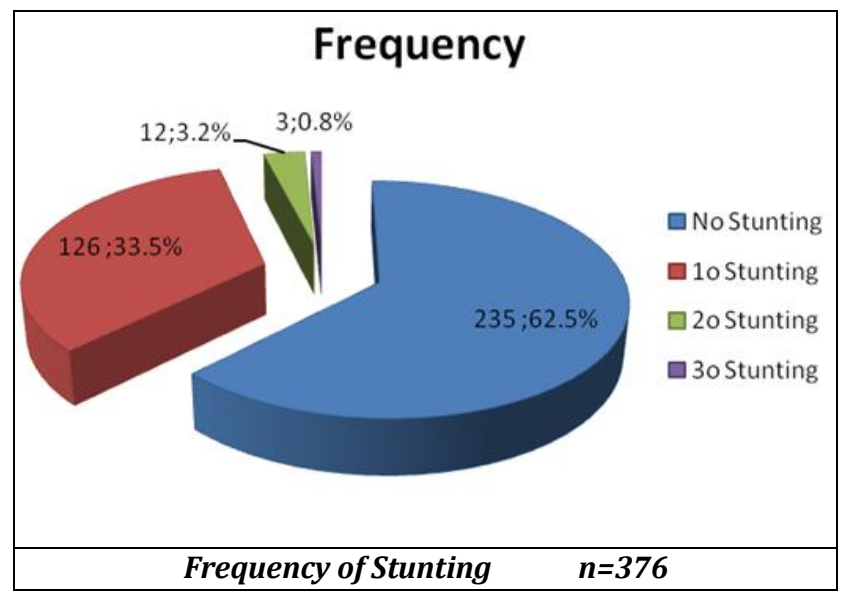

*Of the total 376 children, 235 (62.5\%) had no stunting, 126 (33.5\%) had first degree stunting, 12 (3.2\%) had second degree stunting

According to age wise classification out of 60 children in 1$6 \mathrm{M}$ age group, 46 (76.6\%) were normal, 13 (21.6\%) had 1 o stunting. In the 7-12 M age group, 82 (63\%) had normal height, 45 (34.6\%) had $1^{\circ}$ stunting. Of 186 children in $13-24 \mathrm{M}$ age group, 107 (57.5\%) were normal, 68 (36.5\%) had 10 stunting.

The sex wise distribution showed Among 183 males, 124 (68\%) were normal. 59 male children (32\%) had stunting. Of the 193 females, 111 (57.5\%) had normal height; 82 (42.5\%) had stunting.

Out of the total 376 children with different grades of wasting showed $68.4 \%$ had no wasting, $20.5 \%$ had grade 1 wasting, $8.2 \%$ had grade 2 wasting and $2.9 \%$ had grade 3 wasting.

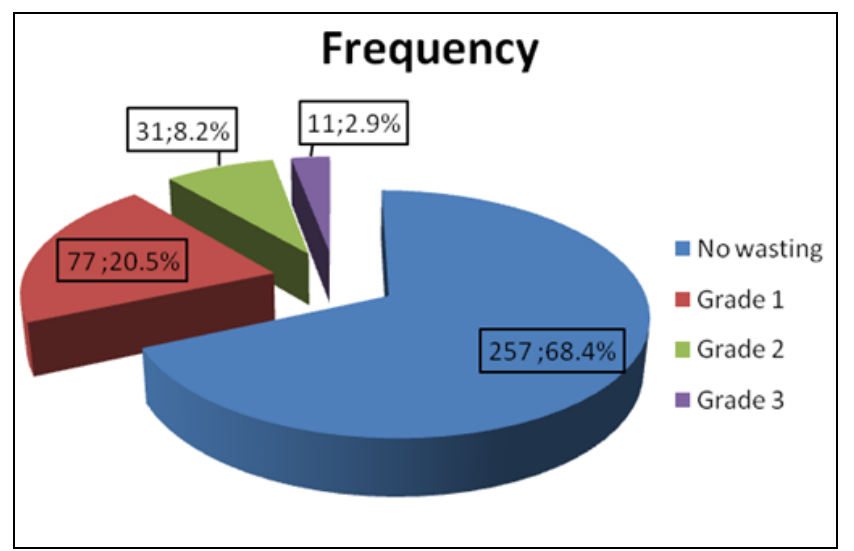

* Of the total 376 children, $68.4 \%$ had no wasting, and 20.5 $\%$ had grade 1 wasting.

In 1-6 $\mathrm{M}$ age group, $66.6 \%$ had no wasting, $23.3 \%$ had grade 1 wasting. Among 7-12 M age group, 64.6\% were normal and $23.8 \%$ had grade 1 wasting. In 13-24-month age group, $71.5 \%$ were normal and $17.2 \%$ had grade 1 wasting. Of the 183 males, 119 (65\%) were normal and 46 (25\%) had grade 1 wasting. Among 193 females, 138 (71.5\%) were normal and $31(16 \%)$ had grade 1 wasting.
Mid Arm Circumference (MAC) was taken only in 13-24month age group for analysis. Of the 186 children in this age group, $55.4 \%$ had no PEM, 37.6\% had moderate PEM and $7 \%$ severe PEM.

In WHO grading, $77.7 \%$ of total children were normal; $18.4 \%$ had moderate PEM and $4 \%$ had severe malnutrition.

\begin{tabular}{|c|c|c|c|c|c|c|}
\hline \multirow{2}{*}{$\begin{array}{c}\text { Grading of } \\
\text { PEM }\end{array}$} & \multicolumn{3}{|c|}{ Birth Weight (kg) } & \multicolumn{2}{|c|}{ Total } \\
\cline { 2 - 7 } & $<\mathbf{2 . 5} \mathbf{~ k g}$ & $\mathbf{2 . 5} \mathbf{~ k g}$ & \multicolumn{2}{|c|}{} \\
\cline { 2 - 7 } & $\mathbf{N o}$ & $\mathbf{\%}$ & $\mathbf{N o}$ & $\mathbf{\%}$ & No: & $\%$ \\
\hline Normal & 23 & 53.5 & 249 & 74.8 & 272 & 72.3 \\
\hline Mild & 10 & 23.3 & 65 & 19.5 & 75 & 19.9 \\
\hline Moderate & 6 & 14.0 & 17 & 5.1 & 23 & 6.1 \\
\hline Severe & 3 & 7.0 & 2 & 0.6 & 5 & 1.3 \\
\hline Very severe & 1 & 2.3 & 0 & 0.0 & 1 & 0.3 \\
\hline Total & $\mathbf{4 3}$ & $\mathbf{1 0 0 . 0}$ & $\mathbf{3 3 3}$ & $\mathbf{1 0 0 . 0}$ & $\mathbf{3 7 6}$ & $\mathbf{1 0 0 . 0}$ \\
\hline Grades of PEM (IAP) in relation to Birth weight \\
\hline
\end{tabular}

${ }^{*}$ Grades of PEM (IAP) in relation to Birth weight. $\dagger-\chi^{2}=$ $26.913 \mathrm{P}<0.001$. $\ddagger$ This table shows there is a significant relation $(\mathrm{p}<0.001)$ between low birth weight and the prevalence of PEM.

*Grades of PEM (IAP) in relation to duration of exclusive breast feeding.

\begin{tabular}{|c|c|c|c|c|c|}
\hline \multirow{2}{*}{$\begin{array}{c}\text { Grading of } \\
\text { PEM }\end{array}$} & \multicolumn{4}{|c|}{$\begin{array}{c}\text { Duration of Exclusive } \\
\text { Breast Feeding }\end{array}$} & \multirow{2}{*}{$\begin{array}{c}\text { Overall } \\
\text { Total }\end{array}$} \\
\cline { 2 - 5 } & $\begin{array}{c}<\mathbf{4} \\
\text { Months }\end{array}$ & $\begin{array}{c}\mathbf{4} \text { M to }< \\
\mathbf{6 M}\end{array}$ & $\begin{array}{c}\mathbf{= 6} \\
\mathbf{M}\end{array}$ & $\begin{array}{c}\mathbf{>} \mathbf{6} \\
\mathbf{M}\end{array}$ & \\
\hline Normal & 36 & 94 & 93 & 2 & 225 \\
\hline Mild & 10 & 29 & 24 & 0 & 63 \\
\hline Moderate & 2 & 6 & 12 & 2 & 22 \\
\hline Severe & 2 & 3 & 0 & 0 & 5 \\
\hline Very severe & 1 & 0 & 0 & 0 & 1 \\
\hline Total & $\mathbf{5 1}$ & $\mathbf{1 3 2}$ & $\mathbf{1 2 9}$ & $\mathbf{4}$ & $\mathbf{3 1 6}$ \\
\hline
\end{tabular}

${ }^{*}$ Grades of PEM (IAP) in relation to duration of exclusive breast feeding among 7-24 months age group $\dagger \chi^{2}=24.362 \mathrm{P}$ $=0.018$

For analysing the relation of PEM and duration of exclusive breastfeeding, only the children in 7-24-month age group were considered. Of the total 316 children in this age group, only 129 (40.8\%) were exclusively breast fed for 6 months and appropriate complementary feeding started. 132 (41.7\%) children were breastfed for at least 4 months but less than the recommended duration of 6 months. 16\% (51) of children were breast fed for less than 4 months.

\begin{tabular}{|c|c|c|c|c|c|c|c|c|c|}
\hline \multirow[b]{2}{*}{$\begin{array}{l}\text { Grading } \\
\text { of PEM }\end{array}$} & \multicolumn{4}{|c|}{ Female } & \multicolumn{4}{|c|}{ Male } & \multirow[b]{2}{*}{$\begin{array}{c}\text { Overall } \\
\text { Total }\end{array}$} \\
\hline & $\stackrel{0}{-1}$ & $\stackrel{\sim}{\mathfrak{1}}$ & $\begin{array}{l}\stackrel{\sim}{N} \\
\ddot{n}\end{array}$ & సٓํㅇ & $\stackrel{0}{\sim}$ & $\frac{\mathfrak{1}}{\mathfrak{1}}$ & $\stackrel{\vec{N}}{\stackrel{H}{\sim}}$ & 苞 & \\
\hline Normal & 22 & 38 & 64 & 124 & 25 & 52 & 71 & 148 & 272 \\
\hline Mild & 10 & 17 & 22 & 49 & 2 & 9 & 15 & 26 & 75 \\
\hline Moderate & 1 & 7 & 7 & 15 & 0 & 3 & 5 & 8 & 23 \\
\hline Severe & 0 & 4 & 1 & 5 & & & & & 5 \\
\hline Very severe & & & & & 0 & 0 & 1 & 1 & 1 \\
\hline \begin{tabular}{|l|} 
Total \\
\end{tabular} & 33 & 66 & 94 & 193 & 27 & 64 & 92 & 183 & 376 \\
\hline Weight for & & 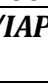 & 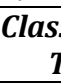 & sificat & ion- & & & 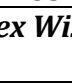 & Cross \\
\hline
\end{tabular}

*Weight for age/IAP classification -Age and sex wise cross tabulation

Comparison between IAP \&WHO classification of PEM 
For comparing WHO and IAP classification, Grade 1 \&Grade 2 PEM in IAP taken together as 'moderate' degree of PEM. Grade 3 \& 4 PEM in IAP taken together as 'severe'.

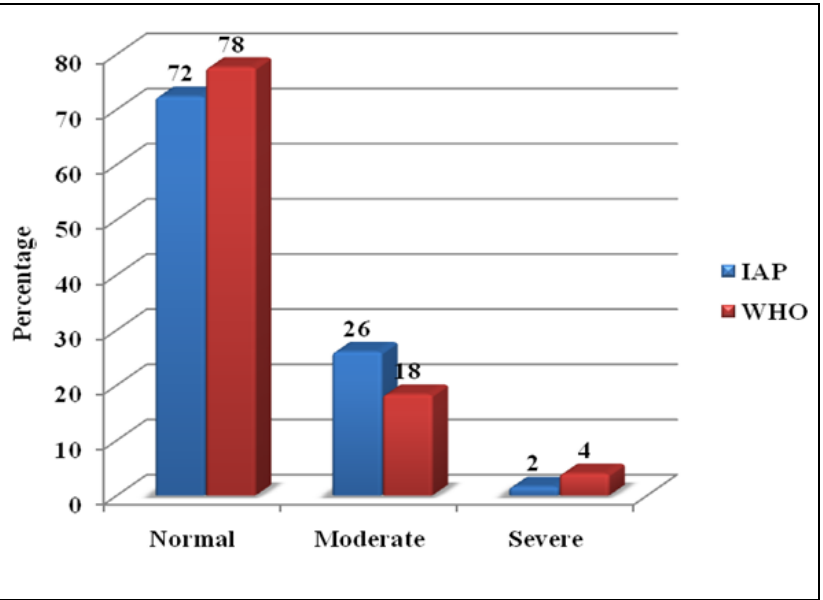

*The overall prevalence of PEM is higher by IAP (28\%) than using WHO chart (22\%). † But the percentage of severe PEM is higher by WHO chart.

In $<6$ months age group, the prevalence of PEM was higher using WHO (28.4\%) standards than using IAP (21.7\%). The difference is statistically significant. Kendall' coefficient of concordance was used to compare IAP and WHO classification. Significant chi square indicates that there is no significant agreement between two classifications. Overall concordance rate is $(47 / 60)=78.3 \%$.

Comparison between IAP \&WHO classification in 7-24 months age group.

\begin{tabular}{|c|c|c|c|c|}
\hline \multirow[b]{2}{*}{$\begin{array}{c}\text { IAP } \\
\text { Classification }\end{array}$} & \multicolumn{3}{|c|}{ WHO Classification } & \multirow[b]{2}{*}{ Total } \\
\hline & $\begin{array}{l}-2 \text { to } 2 \mathrm{Z} \\
\text { Score } \\
\text { (Normal) }\end{array}$ & $\begin{array}{c}-2 \text { to }-3 \mathrm{Z} \\
\text { Score } \\
\text { (Moderate) }\end{array}$ & \begin{tabular}{|c|}
$<-3 \mathrm{Z}$ \\
Score \\
(Severe)
\end{tabular} & \\
\hline Normal & 225 & 0 & 0 & 225 \\
\hline Moderate & 24 & 53 & 8 & 85 \\
\hline Severe & 0 & 0 & 6 & 6 \\
\hline Total & 249 & 53 & 14 & 316 \\
\hline
\end{tabular}

*Comparison between IAP \&WHO classification in 7-24 months age group $\dagger$ Kendall's $W=0.263$.

$\neq$ Chi square $=83.00 \S \mathrm{P}<0.001$.

Kendall' coefficient of concordance was used to compare IAP and WHO classification. Significant chi square indicates that there is significant agreement between two classifications. Overall concordance rate is $(47 / 60)=89.87 \%$. In 7-24-months age group, percentage of PEM by IAP (28.8\%) is higher than that by WHO (21.2\%).

Comparison of sex wise distribution of PEM by WHO \& IAP The percentage of PEM in females is higher than that of males, but the disparity is significantly higher when IAP growth chart is used.

Mid Arm Circumference (MAC) analysed in was taken only in 186 children showed, $55.4 \%$ had no PEM, 37.6\% had moderate PEM and $7 \%$ severe PEM

Among 376 children, $88.5 \%$ had birth weight $\geq 2.5 \mathrm{~kg}$ and $11.5 \%$ had low birth weight. In the normal birth weight category, $74.8 \%$ had normal weight for age, while in those with low birth weight, only $53.5 \%$ were normal. In $<6$ months age group, the prevalence of PEM was higher using WHO (28.4\%) standards than using IAP (21.7\%). The difference is statistically significant. In 7-24-months age group, percentage of PEM by IAP (28.8\%) is higher than that by WHO (21.2\%).

\section{DISCUSSION}

The study included 376 children grouped into three age groups for the ease of analysis. The prevalence of malnutrition as per IAP classification is $27.7 \%$ \& $22.4 \%$ by using WHO. In a study conducted at SAT hospital Thiruvanthapuram by Dr. Jayakumar et $\mathrm{al}^{9}$ the prevalence of Protein Energy Malnutrition was $27.5 \%$ as classified by the IAP which correlates well with our study. As per latest NFHS 3 (20052006) ${ }^{10}$ data, the percentage of children less than 3 years of age who are underweight in Kerala is $21.2 \%$, and the prevalence of 11 PEM was $24 \%$ in rural areas and $15.35 \%$ in urban areas. In a study conducted by Sen P.K. included 1280 under five children of Calcutta the prevalence of Grade 1, Grade 2, \&Grade 3 PEM were $28 \%, 17 \%$ and $7 \%$ respectively.

The sex wise prevalence showed higher grades of PEM more in females. In NFHS- 3 study the prevalence of PEM in females was more as compared to males ( $43.1 \%$ vs 41.9 in moderate grade and $16.4 \%$ vs $15.3 \%$ in severe PEM.). In a community-based study done by Dr. S. Chakraborty, S.B. Gupta, B.et al in U.P. 12 Female children had a higher incidence of PEM.

When the results obtained from both the charts are compared, the prevalence of PEM in 1-6-month age group is higher with WHO growth chart. The percentage of malnutrition in $>6$ months age group steeply rises when IAP growth chart is used as compared to WHO chart. There was significant association between low birth weight and prevalence of PEM. ( $p$ value $<0.001$ ). The study correlates well with NFHS-3 data which states that low birth weight as an important determinant of PEM in India. Kupup PJ Khandekhar $\mathrm{R}^{13}$ conducted a study in Omani children in which low birth weight was found to be a significant predictor of under nutrition.

The percentage of PEM is higher in those who are inadequately breastfed, which is statistically very significant ( $p$ value $<0.018$ ) and there is increased prevalence of severe grades of PEM in this group. Shanti Ghosh et.al ${ }^{14}$ reported lack of exclusive breast feeding in first 6 months and failure to introduce semi solids after 6 months as significant etiological factors for malnutrition in India. Latest UNICEF statistics NOV 200815 shows that lack of exclusive breast feeding for the optimal period as important etiological factor for persistence of malnutrition in India.

There were 4 (1.2\%) children who were exclusively breast fed for more than the recommended 6 months, of which $50 \%$ had normal nourishment while another $50 \%$ had grade 2 PEM. Rama Rao G et al, conducted a study in north eastern India which showed that children who were breastfed for the prescribed optimum duration of 6 months were nutritionally better off than those children who were breastfed even beyond their first birthday. 16

In two studies by Jelliffe ${ }^{17}$ in Caribbean children $11 / 2$ to 2 $1 / 2$ times more PEM was diagnosed using weight than was the case using mid-arm circumference, applying the same standards. In Uganda, Cook 18 found that mid-arm circumference assessment led to $13.5 \%$ false negative PEM diagnoses, and $21 \%$ false positive diagnoses when compared 
to weight for age was used. Though MAC can be used as a tool for assessing under nutrition in community studies it does not shows a constant relationship with weight for age in the same age group. Of the total 376 children, $62.5 \%$ had no stunting, $33.5 \%$ had first degree stunting, 3.2\% had second degree stunting and 3 children $0.8 \%$ had third degree stunting according to Waterlows classification.

In Kerala, children who are less than 3 yearswith stunting as per the NFHS -3 is $26.5 \%$, while $45 \%$ of $<3$ years children are stunted. Though kerala standard is better compared to other states, stunting which is an indicator of chronic malnutrition is still $37.5 \%$ in our study and our healh policies shoud address these issue.

As per NFHS-3, in Kerala $15.6 \%$ of children less than 3 years of age have wasting and this increased to $18.8 \%$ in rural areas which correlates well with our study.

For comparing WHO and IAP classification, Grade 1 \& Grade 2 PEM in IAP taken together as'moderate'degree of PEM. Grade 3 \& 4 PEM in IAP taken together as 'severe'.

The total prevalence of under nutrition in our study group of 376 children by using IAP chart was $(27.7 \%)$ higher as compared to WHO growth chart $(22.7 \%)$. H.P.S Sachdev reported a prevalence $65.4 \%$ and $61.2 \%$ malnutrition using IAP and WHO standards respectively, IAP standard showing more malnutrition than WHO standards.

Using the IAP chart the percentage of 'moderate' malnutrition was $26 \%$ and 'severe' malnutrition was $1.6 \%$. In the same study group the prevalence of moderate and severe malnutrition by WHO were $18.4 \%$ and $4 \%$ respectively. So the prevalence of severe PEM is higher with WHO chart. H.P.S Sachdev $^{19}$ showed in his study the percentage of severe malnutrition was $33.3 \%$ and $17.1 \%$ with WHO SD and IAP standards respectively. Prema Ramachandran, in their study reported the prevalence of severe under nutrition is lowest by IAP standards and higher with WHO standards (2006).

In 1-6-months age group the prevalence of PEM was higher with WHO standards when compared with IAP standards. The difference is statistically significant. In the rest of the study group the prevalence is just reverse. This finding correlates well with that obtained in a study by Prema Ramachandran et al 20 in which computed underweight rates using WHO (2006) standards are higher as compared to the computed underweight rates using IAP standards in the first six months. After first year the prevalence of underweight rates computed from the WHO standards is lower than the underweight rates computed using the IAP standards. This may be due the fact that the IAP standards are based on data from formula fed infants.

In the prevalence of PEM in males as per IAP is $19.2 \%$ while that of females is $36 \%$. By WHO, in males the prevalence of PEM is $18.6 \%$ while that in females is $26 \%$. Thus, the prevalence of PEM in females is shown to be significantly higher when IAP classification is used. The fact that IAP uses unisex Harvard standards while WHO uses gender specific growth charts is the reason for this disparity. In a comparison study by. Shankar Prinja, shows the same results. ${ }^{21}$

Prema Ramachandran study shows prevalence of under nutrition based on WHO standards clearly brings out the importance of too early introduction of breast milk substitutes, too late introduction of complementary feeds as major factors associated with rising prevalence of under nutrition in children. Thus, the use of WHO (2006) growth standards can make an important contribution in clearly bringing into focus the importance of increasing investment in nutrition and health education and health care to improve infant and young child feeding habits during the critical period of growth which can result in substantial reduction in under nutrition rates in preschool children.

The growth charts based on the new WHO Standards (2006) ${ }^{22}$ describe how children should grow, which is a prescriptive approach, not just a descriptive one. They show that all children can attain a similar standard of height and weight with adequate feeding and healthcare. It is a more proactive way of evaluating child growth. A key characteristic of the new standard is that it establishes breast feeding as the biological norm. The WHO standards are useful for detecting both under nutrition and obesity, thus addressing the double burden of nutrition. The new WHO standards show a smaller gender bias in underweight prevalence than the IAP growth curves and during the first six months it scores over breast fed infants than IAP charts.

\section{CONCLUSION}

1. The prevalence of under nutrition in 1-24 months of age is $27.7 \%$ as per IAP standards and $22.4 \%$ by WHO-Z score.

2. Under nutrition and stunting are more prevalent among female children.

3. Low birth weight has been found to have statistically significant association with Protein Energy Malnutrition.

4. Though Kerala's health standards are high only $41 \%$ of children are exclusively breast fed for the optimum period of six months.

5. Lack of exclusive breast feeding for optimum period has deleterious impact on the nutritional status of children.

6. $37.5 \%$ of children are stunted indicating greater degree of chronic malnutrition.

7. $31.6 \%$ of children were wasted and wasting is more in males.

8. The total prevalence of PEM is higher on using IAP chart, but in 1-6 months age group WHO growth chart detects more PEM.

9. IAP growth chart detects a higher percentage of PEM in female children than WHO chart.

10. The disparity in results obtained with IAP and WHO charts may be due to the fact that IAP standards are based on formula fed infants (unisex Harvard standards).

\section{ACKNOWLEDGEMENT}

We thank all the parents for their cooperation during the study. We would like to acknowledge all the staff members from, Department of Paediatrics, Department of Preventive and Social Medicine and Thalikulam Panchayath office who have helped us during this study.

\section{REFERENCES}

[1] C-14 Population in five year age-group by residence and sex. New Delhi: Office of the Registrar General and Census Commissioner, Ministry of Home Affairs, Government of India, 2011. http://www.censusindia. gov.in/2011census/C-series/C-14.html. Accessed July 11, 2015.

[2] Arnold F, Parasuraman S, Arokiasamy P, et al. Nutrition in India. National Family Health Survey (NFHS3), India, 2005-06. Mumbai. hetv.org/ india/nfhs/index.html. Accessed September 15, 2015. 
[3] Kliegman RM, Stanton BF, Joseph W, et al. Nelson Textbook of Pediatrics. 19 ${ }^{\text {th }}$ edn. Elsevier 2011: p. 1718.

[4] Elizabeth KE. Nutrition and child development. $3^{\text {rd }}$ edn. Paras Publishing 2007: p. 133-87.

[5] Frank DA, Zeisel SH. Failure to thrive. Pediatr Clin North Am 1988;35(6):1187-206.

[6] Khokhar A, Singh S, Talwar R, et al. A study of malnutrition among children aged 6 months to 2 years from a resettlement colony of Delhi. Indian J Med Sci 2003;57(7):286-9.

[7] Children in India 2012- a statistical appraisal: chapter 4.

http://mospi.nic.in/mospi_new/upload/Children_in_I ndia_2012.pdf

[8] Unicef, India. The children nutrition. http://www.unicef.org/india/children_2356.htm

[9] Varghese LRT, Jayakumar C, Jayaprakash R, et al. Malnutrition and obesity on a paediatric ward of tertiary teaching hospital in Kerala, India. Australasian Med J 2009;7(1):29-32.

[10] National Family Health Survey (NFHS-3), 2005-06, Volume 1. India. www.nfhsindia.org.

[11] Sen PK. Nutritional status of under five children in an urban slum community of Calcutta. Indian J Public Health 1994;38(3):113-4.

[12] Chakraborty S, Gupta SB, Chaturvedi B, et al. A study of protein energy malnutrition (PEM) in Children (0 to 6 Year) in a rural population of Jhansi district (U.P). Indian J of Community Med 2006;31(4):291-2.

[13] Kurup PJ, Khandekar R. Low birth weight as a determinant of protein energy malnutrition in "0-5 years" Omani children of South Batinah region, Oman. Saudi Med J 2004;25(8):1091-6.
[14] Ghosh S, Shah D. Nutritional problems in urban slum children. Indian Pediatrics 2004;41(7):682-96.

[15] Mendelson S, Chaudhuri S. Child malnutrition in India: Why does it persist? http://www. cini. org.uk/ child_malnutrition.html44.

[16] Rao GR, Ladusingh L, Pritamjit R. Nutritional status of children in North-East India. Asia Pacific Population Journal 2004;19(3):39-56.

[17] Jelliffe EF, Jelliffe DB. The arm circumference as a public health index of protein calorie malnutrition of early childhood. J Trop Pediat 1969;15(4):177-260.

[18] Cook R. The arm circumference in a field survey in Ankole, Uganda. J Trop Pediat 1969;15:198-200.

[19] Sachdev HPS. Assessing child malnutrition some basic issues. Bulletin of The Nutrition Foundation of India 1995;16(4):1-6.

[20] Ramachandran P. Adoption of WHO Growth Standards (2006) - Issues and Implications. Bulletin of the Nutrition Foundation of India. Number 2, Volume 28. April 2007. http://nutritionfoundationofindia.res.in/pdfs/Apr200 7.pdf

[21] Prinja S, Thakur JS, Bhatia SS. Pilot testing of WHO child growth standards in Chandigarh: implications for India's child health programmes. Bulletin World Health Organization 2009;87(2):116-22.

[22] WHO, Multicentre Growth Reference Study Group. Enrolment and baseline characteristics in the WHO multicentre growth reference study. Acta Paediatr 2006;95(Suppl 450):7-15. 